\title{
Trichodysplasia Spinulosa Polyomavirus in Respiratory Tract of Immunocompromised Child
}

\section{Arwa A. Bagasi, Tasneem Khandaker, Gemma Clark, Terry Akagha, Jonathan K. Ball, William L. Irving, C. Patrick McClure}

\begin{abstract}
Author affiliations: King Saud University, Riyadh, Saudi Arabia (A.A. Bagasi); University of Nottingham, Nottingham, UK (A.A. Bagasi, T. Khandaker, T. Akagha, J.K. Ball, W.L. Irving, C.P. McClure); Nottingham University Hospitals NHS Trust, Nottingham (G. Clark, W.L. Irving)
\end{abstract}

DOI: https://doi.org/10.3201/eid2409.180829

Trichodysplasia spinulosa polyomavirus causes trichodysplasia spinulosa, a skin infection, in immunocompromised persons, but the virus is rarely detected in respiratory samples. Using PCR, we detected persistent virus in respiratory and skin samples from an immunocompromised boy with respiratory signs but no characteristic skin spicules. This virus may play a role in respiratory illness.

$\mathrm{T}$ richodysplasia spinulosa is a rare skin disease that occurs exclusively in immunocompromised persons. It is characterized by facial keratotic spicules formed by trichohyalin accumulation in the inner root sheath cells of affected hair follicles. In 1999, electron microscopy identified a novel polyomavirus, subsequently named trichodysplasia spinulosa polyomavirus (TSPyV) or human polyomavirus 8 , in sections of skin spicules of a solid organ transplant patient (1); in 2010, the virus was more completely characterized (2). TSPyV is 1 of 5 polyomaviruses associated with human diseases, particularly those that affect immunocompromised persons (3). Although worldwide seroprevalence of TSPyV antibodies among the general population is estimated at $70 \%$ (4) and a respiratory route of infection has been hypothesized $(5,6)$, as of 2015 , only 32 cases of trichodysplasia spinulosa had been reported (7), suggesting that other pathology caused by TSPyV may have gone undiagnosed. We describe PCR detection of TSPyV in an immunocompromised boy with respiratory signs and symptoms.

To elucidate potential causes of undiagnosed viral respiratory infection, during January 2015-February 2016, we used a panpolyomavirus degenerate primer PCR to screen archived samples for polyomavirus. The archived samples were nucleic acid of respiratory specimens from 218 children 6 months to 5 years of age, previously negative for typical respiratory viruses in a panel used for routine diagnosis (online Technical Appendix, https://wwwnc.cdc. gov/EID/article/24/9/18-0829-Techapp1.pdf). Of the 218 samples screened in 22 pools, we obtained positive results for polyomavirus in 1 pool and, subsequently, 1 sample (from the patient reported here). Subsequent Sanger sequencing and BLAST (http://blast.ncbi.nlm.nih.gov/Blast. cgi) analysis of the 274-bp degenerate primer PCR product indicated that the sample contained TSPyV. The complete genome of this TSPyV strain was amplified in 4 overlapping PCR fragments and Sanger sequenced (online Technical Appendix). Phylogenetic analysis of the assembled complete 5,232-nt genome with all available 23 reference sequences revealed that the TSPyV strain was most closely related to TSPyV 1312, which had been isolated in 2012 in Dallas, Texas, USA (online Technical Appendix), but bootstrap support was limited because of the highly conserved nature of TSPyV genomes.

The patient from whom this TSPyV-positive sample was collected was a 4-year-old boy in Nottinghamshire, United Kingdom, who had common acute lymphoblastic leukemia and was receiving maintenance chemotherapy during the study period. Retrospective clinical analysis for March 2014-February 2016 revealed that the child had had frequent cough with fever and coryzal symptoms of varying severity (Table). Concurrently collected nasopharyngeal aspirate and throat swab specimens were negative for bacterial and viral pathogens routinely tested for, except at the start of the study period, when rhinovirus and adenovirus were detected, and the end of the period, when rhinovirus and respiratory syncytial virus were detected (Table). No bacteria were cultured from paired specimens. On this basis, in conjunction with unremarkable physical examination and radiologic findings and stable neutrophil and leukocyte counts (data not shown), the patient's respiratory signs were treated conservatively on an outpatient basis. However, on 2 occasions (August and November 2015), the child required hospital admission, without and with co-infection, respectively.

Further retrospective laboratory investigation found that all 11 additional samples collected from this patient during November 2014-2015 were positive for TSPyV, with co-infection at the 4 time points (November and December 2014, September and November 2015); testing showed fluctuating cycle threshold $\left(\mathrm{C}_{\mathrm{t}}\right)$ levels on quantitative PCR (Table; online Technical Appendix). Of note, various forms of rashes appeared in different anatomic regions of the patient but did not resemble the characteristic appearance of trichodysplasia spinulosa and, thus, did not raise any clinical suspicion for this condition. Indeed, retrospective testing found that a single skin swab sample taken from a suspected viral rash (site undocumented) that looked like blisters and 
Table. Clinical and laboratory data from TSPyV-positive patient, Nottinghamshire, United Kingdom, November 2014-2015*

\begin{tabular}{|c|c|c|c|c|c|c|}
\hline $\begin{array}{l}\text { Collection } \\
\text { date }\end{array}$ & Sample type & $\begin{array}{l}\text { Signs and symptoms at } \\
\text { time of sample collection }\end{array}$ & $\begin{array}{c}\text { Documented skin } \\
\text { lesion }\end{array}$ & Hospital admission & $\begin{array}{l}\text { Viral/bacterial } \\
\text { co-infection }\end{array}$ & $\begin{array}{l}\text { TSPyV } \\
\mathrm{C}_{\mathrm{t}} \text { value } \\
\end{array}$ \\
\hline \multicolumn{7}{|l|}{2014} \\
\hline Nov & Throat swab & Cough, sore throat, fever & $\begin{array}{l}\text { Tiny skin colored } \\
\text { pustules on hand }\end{array}$ & Not required & Rhinovirus & 31.83 \\
\hline Dec & NPA & Cough, fever & None & Not required & Adenovirus & 31.17 \\
\hline \multicolumn{7}{|l|}{2015} \\
\hline Jan & Skin swab & None recorded & $\begin{array}{l}\text { Suspected varicella } \\
\text { zoster virus rash }\end{array}$ & Not required & None & 24.97 \\
\hline Feb & NPA & Dry cough, fever & None & Not required & None & 31.23 \\
\hline Mar & Throat swab & $\begin{array}{l}\text { Dry cough, } \\
\text { coryzal symptoms }\end{array}$ & None & Not required & None & 21.43 \\
\hline Jul† & Throat swab & Cough with runny nose & None & Not required & None & 23.90 \\
\hline Jult & NPA & Cough with runny nose & None & Not required & None & 22.70 \\
\hline Julf & NPA & Dry cough, fever & $\begin{array}{l}\text { Few blisters } \\
\text { on fingers }\end{array}$ & Not required & None & 22.30 \\
\hline Julł & Throat swab & Dry cough, fever & $\begin{array}{l}\text { Few blisters } \\
\text { on fingers }\end{array}$ & Not required & None & 25.37 \\
\hline Aug & Throat swab & Cough, fever (high) & $\begin{array}{l}\text { Erythematous } \\
\text { rash with tiny white } \\
\text { center on face }\end{array}$ & Hospitalized $4 \mathrm{~d}$ & None & 21.47 \\
\hline Sep & NPA & Cough & None & Not required & Rhinovirus & 26.87 \\
\hline Nov & Throat swab & $\begin{array}{l}\text { Cough, wheeze, fever } \\
\text { (high), coryzal symptoms }\end{array}$ & Rash across chest & Hospitalized $5 \mathrm{~d}$ & $\begin{array}{l}\text { Respiratory } \\
\text { syncytial virus }\end{array}$ & 23.45 \\
\hline
\end{tabular}

was queried as chickenpox was positive for TSPyV with a low $\mathrm{C}_{\mathrm{t}}$ value of 24.97 (Table). Thus, it is conceivable that this rash represented the early papular stages of a trichodysplasia spinulosa lesion that did not progress to the characteristic spicules.

Previously, TSPyV has almost exclusively been associated with pathology of the skin (4); but 4 reports indicate its isolation from blood (6) and respiratory samples, suggesting a potential transmission route $(5,8-$ 10). However, respiratory signs and symptoms were observed only in patients co-infected with another virus. In contrast, the patient we report had persistent respiratory signs and symptoms and concomitant TSPyV-positive (by PCR) respiratory samples in conjunction with varying forms of skin lesion lacking the characteristic spicule form of trichodysplasia spinulosa. However, it is difficult to assess the virus pathogenicity in the absence of any supportive cell culture results. Hence, the potential of TSPyV to cause respiratory signs and symptoms needs further investigation and surveillance. The relatively low $\mathrm{C}_{\mathrm{t}}$ values (and thus high viral loads) of TSPyV DNA obtained from this patient in the absence of positive results for any other microbial agents may suggest an etiologic role of the TSPyV in respiratory pathogenesis. The fact that TSPyV skin disease can be effectively treated with antiviral medication, such as cidofovir (6), presents potential for treatment of respiratory manifestations of TSPyV infection.

This study was funded internally by the University of Nottingham, UK, as part of a master of science degree project.

\section{About the Author}

Ms. Bagasi is a PhD student at the University of Nottingham. Her research interests are epidemiology and cellular entry of viral infections.

\section{References}

1. Haycox CL, Kim S, Fleckman P, Smith LT, Piepkorn M, Sundberg JP, et al. Trichodysplasia spinulosa - a newly described folliculocentric viral infection in an immunocompromised host. J Investig Dermatol Symp Proc. 1999;4:268-71. http://dx.doi.org/ 10.1038/sj.jidsp.5640227

2. van der Meijden E, Janssens RW, Lauber C, Bouwes Bavinck JN, Gorbalenya AE, Feltkamp MC. Discovery of a new human polyomavirus associated with trichodysplasia spinulosa in an immunocompromized patient. PLoS Pathog. 2010;6:e1001024. http://dx.doi.org/10.1371/journal.ppat.1001024

3. Nguyen KD, Lee EE, Yue Y, Stork J, Pock L, North JP, et al. Human polyomavirus 6 and 7 are associated with pruritic and dyskeratotic dermatoses. J Am Acad Dermatol. 2017 76:932-40 e3. http://dx.doi.org/10.1016/j.jaad.2016.11.035

4. Kazem S, van der Meijden E, Feltkamp MC. The trichodysplasia spinulosa-associated polyomavirus: virological background and clinical implications. APMIS. 2013;121:770-82. http://dx.doi.org/ 10.1111/apm.12092

5. Bialasiewicz S, Byrom L, Fraser C, Clark J. Potential route of transmission for trichodysplasia spinulosa polyomavirus. J Infect Dis. 2017;215:1175-6. http://dx.doi.org/10.1093/infdis/jix078

6. van der Meijden E, Horváth B, Nijland M, de Vries K, Rácz EK, Diercks GF, et al. Primary polyomavirus infection, not reactivation, as the cause of trichodysplasia spinulosa in immunocompromised patients. J Infect Dis. 2017;215:1080-4.

7. Wu JH, Nguyen HP, Rady PL, Tyring SK. Molecular insight into the viral biology and clinical features of trichodysplasia spinulosa. $\mathrm{Br}$ J Dermatol. 2016;174:490-8. http://dx.doi.org/10.1111/bjd.14239

8. Tsuzuki S, Fukumoto H, Mine S, Sato N, Mochizuki M, Hasegawa H, et al. Detection of trichodysplasia 
spinulosa-associated polyomavirus in a fatal case of myocarditis in a seven-month-old girl. Int J Clin Exp Pathol. 2014;7:5308-12.

9. Siebrasse EA, Bauer I, Holtz LR, Le BM, Lassa-Claxton S, Canter C, et al. Human polyomaviruses in children undergoing transplantation, United States, 2008-2010. Emerg Infect Dis. 2012;18:1676-9. http://dx.doi.org/10.3201/eid1810.120359

10. Rockett RJ, Sloots TP, Bowes S, O'Neill N, Ye S, Robson J, et al. Detection of novel polyomaviruses, TSPyV, HPyV6, HPyV7, HPyV9 and MWPyV in feces, urine, blood, respiratory swabs and cerebrospinal fluid. PLoS One. 2013;8:e62764. http://dx.doi.org/ 10.1371/journal.pone.0062764

Address for correspondence: C. Patrick McClure, University of Nottingham, School of Life Sciences, Queen's Medical Centre, West Block A Floor, Nottingham, NG7 2UH, UK; email: patrick.mcclure@nottingham.ac.uk

\section{Wohlfahrtiimonas chitiniclastica Bacteremia in Hospitalized Homeless Man with Squamous Cell Carcinoma}

\section{Yuichi Katanami, Satoshi Kutsuna, Maki Nagashima, Saho Takaya, Kei Yamamoto, Nozomi Takeshita, Kayoko Hayakawa, Yasuyuki Kato, Shuzo Kanagawa, Norio Ohmagari}

Author affiliation: National Center for Global Health and Medicine, Tokyo, Japan

DOI: https://doi.org/10.3201/eid2409.170080

We report a case of Wohlfahrtiimonas chitiniclastica bacteremia in an elderly man in Japan who had squamous cell carcinoma. Blood cultures were initially negative for W. chitiniclastica but were positive on day 20. Careful attention needs to be paid to this organism in patients who have chronic wounds with maggots.

$\mathrm{W}_{\mathrm{i}}$ e report Wohlfahrtiimonas chitiniclastica bacteremia in a 75-year-old man in Japan who had squamous cell carcinoma on his shoulder. In September 2016, an unidentified patient was found unconscious on the ground by a passerby and admitted to the emergency department of the National Center for Global Health and Medicine (Tokyo, Japan). He had a necrotic lesion on his left shoulder with maggots. Blood analysis showed leukocytosis (26.61 $\times 10^{9}$ cells $/ \mathrm{L}$ [reference range $3.30-8.60 \times 10^{9}$ cells $\left./ \mathrm{L}\right]$ ), thrombocytosis $\left(626 \times 10^{9} / \mathrm{L}\right.$ [reference range 158-348 $\times$ $10^{9} / \mathrm{L}$ ]), anemia (hemoglobin, $9.6 \mathrm{~g} / \mathrm{dL}$ [reference range 13.7-6.8 $\mathrm{g} / \mathrm{dL}]$ ), and elevated C-reactive protein (87.9 $\mathrm{mg} / \mathrm{L}$ [reference range $0.00-1.40 \mathrm{mg} / \mathrm{L}$ ]). Albumin was $2.4 \mathrm{~g} / \mathrm{dL}$ (reference range $4.1-5.1 \mathrm{~g} / \mathrm{dL}$ ) and calcium was $12.6 \mathrm{mg} / \mathrm{dL}$ (reference range $8.8-10.1 \mathrm{mg} / \mathrm{dL}$ ). He was diagnosed with disturbance of consciousness caused by hypercalcemia and was hospitalized.

After saline infusion and intravenous cefazolin (3 $\mathrm{g} / \mathrm{d})$ were initiated, the patient's condition improved. A blood culture taken at the time of admission grew Peptoniphilus harei. A swab culture of the ulcer site grew Proteus mirabilis, Morganella morganii, and Kerstersia gyiorum. A biopsy was performed on day 3 , and the patient was diagnosed with squamous cell carcinoma. Enhanced computed tomography scanning revealed an ulcer and ring-enhancing lesion on his left shoulder (which was suspected of being a tumor or abscess) and multiple enlarged lymph nodes and $10-\mathrm{mm}$ pulmonary nodules in the right lung.

On day 20, the patient had fever and disturbance of consciousness; therefore, he was transferred to the Infectious Disease department of the hospital. Intravenous therapy with vancomycin $(1.5 \mathrm{~g} / \mathrm{d})$, cefepime $(3 \mathrm{~g} / \mathrm{d})$, and metronidazole $(1,500 \mathrm{mg} / \mathrm{d})$ was initiated, and the patient's fever and consciousness improved. Two cultures of blood taken on day 20 grew P. mirabilis, M. morganii, Streptococcus anginosus, Streptococcus agalactiae, Bacteroides fragilis, and gram-negative rods. After we obtained the culture results, vancomycin was stopped in accordance with the susceptibility test results. We identified the gramnegative rods as $W$. chitiniclastica by using matrix-assisted laser desorption/ionization time-of-flight mass spectrometry (Bruker Daltonics, Billerica, MA, USA), which showed scores of 2.239. We further confirmed the isolate to be $W$. chitiniclastica by using $16 \mathrm{~S}$ rRNA sequencing; the isolate was $99.08 \%$ identical to strain S5 (GenBank accession no. AM397063). We assessed the isolate's antimicrobial susceptibility profile (Table). The patient improved and was later discharged to another hospital.

W. chitiniclastica is a gram-negative, short, facultative anaerobic, straight-rod gammaproteobacterium that was first isolated from the parasitic fly Wohlfahrtia magnifica (1). This fly has not been reported in Japan. However, $W$. chitiniclastica has also been isolated from the Chrysomya megacephala fly, and this species has been reported in Japan (2), and from from the Musca domestica housefly, which is widely distributed all over the world (3). Campisi et al. reported that the Lucilia sericata fly might be a vector for $W$. chitiniclastica (4); this fly is common and widely distributed throughout Japan, and a 